\title{
Maternal and fetal outcome in abruptio placentae at a tertiary care centre: a retrospective analysis
}

\section{Jessica C. Fernandes, Nandini Gopalakrishna*}

Department of Obstetrics and Gynaecology, M. S. Ramaiah Medical College and Hospitals, Bangalore, Karnataka, India

Received: 28 July 2021

Revised: 03 September 2021

Accepted: 04 September 2021

\author{
*Correspondence: \\ Dr. Nandini Gopalakrishna, \\ E-mail: nandinigopalakrishna@gmail.com
}

Copyright: ( ) the author(s), publisher and licensee Medip Academy. This is an open-access article distributed under the terms of the Creative Commons Attribution Non-Commercial License, which permits unrestricted non-commercial use, distribution, and reproduction in any medium, provided the original work is properly cited.

\begin{abstract}
Background: Placental abruption is a major obstetric complication leading to increased risk of maternal and neonatal morbidity and mortality globally. Placental abruption is traditionally defined as premature separation of a normally implanted placenta after 20 weeks of gestation and before delivery of the fetus. Early recognition of the risk factors, timely diagnosis and early intervention can significantly reduce maternal and fetal morbidity and mortality. This study was aimed to identify the associated risk factors with abruptio placenta and to analyse the maternal and perinatal outcome in abruptio placenta.

Methods: This was a retrospective observational study, from Jan 2016 to Dec 2019 at M.S. Ramaiah medical college and hospitals, Bangalore.

Results: In our study, the incidence of abruptio placenta was $0.95 \%$. Majority of our patients were between 20-24 years $(41.5 \%)$. Primigravidae accounted for $46.15 \%$ of the cases. The unbooked cases were $92 \%$. The commonest risk factor was hypertension complicating pregnancy which accounted for $26 \%$. The live births were $64 \%$. Postpartum haemorrhage was one of the major complications in our study. There was no maternal mortality, probably due to early intervention and availability of blood and blood products.

Conclusions: Timely diagnosis and appropriate intervention preferably in tertiary care centre will significantly reduce mortality and morbidity in both mother and fetus.
\end{abstract}

Keywords: Abruptio placenta, postpartum haemorrhage, Disseminated intravascular coagulation

\section{INTRODUCTION}

Placental abruption is a major obstetric complication leading to increase in maternal and neonatal morbidity and mortality globally. ${ }^{1}$ Placental abruption is a serious obstetric complication which is characterized by separation of a normally situated placenta after 20 weeks of gestation and prior to the birth of the fetus. ${ }^{2}$ Maternal complications include haemorrhagic shock, disseminated intravascular coagulation, renal failure, ischemic necrosis of the distal organs and death. ${ }^{3}$ Fetal complications include hypoxia , anemia, growth restriction, prematurity, neuro-developmental problems, and fetal death. ${ }^{4-6}$
The exact etiology of abruption is unknown but the risk factors such as high parity, advanced maternal age, low socioeconomic status, cigarette smoking, abdominal trauma, alcohol use, cocaine use, maternal hypertension, polyhydramnios, multiple pregnancy, thrombophilias and prior pregnancy with abruption have all been identified. ${ }^{3}$ Abruption is characterized by acute onset, rapid progress and thereby causing high risk to both mother and fetus. Despite its clinical significance there are no reliable diagnostic tests or biomarkers to predict or prevent the occurrence of abruption. Maternal and fetal survival depends on early diagnosis and intervention. Placental abruption may be revealed when blood trickles between 
the membranes and escapes thorough the vagina or concealed when blood collects behind the placenta with no evidence of vaginal bleeding. It may be of mixed type with both revealed and concealed haemorrhage.

\section{Objectives}

This study was aimed to evaluate the clinical profile of patients with abruptio placentae and to analyse the maternal and perinatal outcome in these cases.

\section{METHODS}

The study was conducted at department of obstetrics and gynaecology in M. S. Ramaiah medical college and hospitals, Bangalore from January 2016 to December 2019. It was a retrospective study. The data was collected from the labour room register, OT register and patient case notes from medical records department.

\section{Inclusion criteria}

All patients admitted with suspicion of abruption after 28 weeks of gestation were studied. Abruption was diagnosed clinically in those who presented with vaginal bleeding, tense and tender abdomen and confirmed following delivery by examination of the placenta or presence of retroplacental clots.

\section{Exclusion criteria}

All patients with gestational age less than 28 weeks , diagnosed with placenta previa and bleeding due to local genital tract lesions.

\section{Procedure}

The details regarding demographics, parity, gestational age, clinical presentation and maternal risk factors were collected. All patients underwent detailed clinical examination, obstetric examination and pelvic assessment. Necessary investigations were done and bedside ultrasound was done. Ultrasound, though a poor imaging modality to diagnose abruption, helped in assessing the amount of retroplacental clot. All patients were assessed for severity of abruption and managed depending on the maternal and fetal condition. The maternal complications including post partum haemorrhage, disseminated intravascular coagulation, number of blood and blood products received were analyzed. Fetal complications including still birth, Intra uterine fetal demise, neonatal death, prematurity, admission to Neonatal intensive care unit were analyzed.

\section{Statistical analysis}

All information entered and analyzed using Microsoft excel software. Descriptive statistics of risk factors were analyzed and summarized in terms of percentage

\section{RESULTS}

The total numbers of deliveries from January 2016 to December 2019 were 6773. Abruptio placenta was seen in 65 cases which accounted for $0.95 \%$. In our study, $41.53 \%$ were in the 20-24 years age group. Primigravidae accounted for $46.15 \%$ of the cases. The unbooked patients accounted for $92.3 \%$. Gestational hypertension and preeclampsia were found in $26.15 \%$. Caesarean section was the mode of delivery in $49.23 \%$ and vaginal delivery in $50.71 \%$. In our study the liver births was $64.17 \%$. In our study revealed haemorrhage accounted for $70.76 \%$. Postpartum haemorrhage was the most common complication associated with abruption $16.92 \%$.

Table 1: Age distribution of patients with abruption.

\begin{tabular}{|lll|}
\hline Age (years) & $\mathbf{N}$ & \% \\
\hline $\mathbf{2 0}$ & 2 & 3 \\
\hline $\mathbf{2 1 - 2 4}$ & 27 & 41.53 \\
\hline $\mathbf{2 5 - 2 9}$ & 19 & 29.23 \\
\hline $\mathbf{3 0}$ & 17 & 26.15 \\
\hline
\end{tabular}

Table 2: Association of Parity index with abruption.

\begin{tabular}{|lll|}
\hline Parity & N & $\%$ \\
\hline Primigravida & 30 & 46.15 \\
\hline Gravida 2 & 16 & 24.61 \\
\hline Gravida 3 and above & 19 & 29.23 \\
\hline
\end{tabular}

Table 3: Number of patients based on booking status.

\begin{tabular}{|lll|}
\hline Bookings & N & $\%$ \\
\hline Booked & 5 & 7.69 \\
\hline Unbooked & 60 & 92.30 \\
\hline
\end{tabular}

Table 4: Risk factors related to abruption.

\begin{tabular}{|lll|}
\hline Risk factors & N & $\%$ \\
\hline PIH and PE & 17 & 26.15 \\
\hline Previous LSCS & 9 & 13.84 \\
\hline PPROM & 3 & 4.61 \\
\hline Multiple gestation & 2 & 3.07 \\
\hline Gestational diabetes mellitus & 1 & 1.5 \\
\hline Unexplained & 33 & 50.76 \\
\hline $\begin{array}{l}\text { PIH and PE (pregnancy induced hypertension and } \\
\text { preeclampsia), PPROM (preterm } \\
\text { membranes) }\end{array}$ & prelabour rupture of \\
\hline
\end{tabular}

Table 5: Mode of delivery.

\begin{tabular}{|lll|}
\hline Mode of delivery & $\mathbf{N}$ & $\%$ \\
\hline Vaginal delivery & 28 & 43.07 \\
\hline Instrumental delivery & 5 & 7.69 \\
\hline $\begin{array}{l}\text { Lower segment caesarean } \\
\text { section }\end{array}$ & 32 & 49.23 \\
\hline
\end{tabular}


Table 6: Fetal outcome in patients with abruption.

\begin{tabular}{|l|l|l|}
\hline Fetal out come & $\mathbf{N}$ & $\%$ \\
\hline Live & 43 & 64.17 \\
\hline Still Birth & 1 & 1.49 \\
\hline $\begin{array}{l}\text { Intra uterine fetal } \\
\text { death }\end{array}$ & 23 & 34.32 \\
\hline
\end{tabular}

Table 7: Distribution based on types of abruption.

\begin{tabular}{|l|l|l|}
\hline Type & N & $\%$ \\
\hline Concealed & 7 & 10.76 \\
\hline Revealed & 46 & 70.76 \\
\hline Mixed & 12 & 18.46 \\
\hline
\end{tabular}

Table 8: Complications associated with abruption.

\begin{tabular}{|l|l|l|}
\hline $\begin{array}{l}\text { Complications } \\
\text { Post partum } \\
\text { haemorrhage }\end{array}$ & $\mathbf{N}$ & $\%$ \\
\hline $\begin{array}{l}\text { Rupture uterus with } \\
\text { PPH }\end{array}$ & 1 & 16.92 \\
\hline $\begin{array}{l}\text { Disseminated } \\
\text { intravascular } \\
\text { coagulation }\end{array}$ & 1 & 1.53 \\
\hline Renal failure & 0 & 1.53 \\
\hline
\end{tabular}

\section{DISCUSSION}

Placental abruption is a major cause of obstetric haemorrhage. Placental abruption is one of the serious complications of pregnancy, as it leads to both poor maternal and fetal outcome. ${ }^{6}$ The incidence of abruption was $0.95 \%$ in our study. The incidence was $0.61 \%$ as reported by Saquib et al. ${ }^{1}$ In our study, $71 \%$ were between 21-29 yrs compared to a study by Cande Ananth et al where $52 \%$ were between $25-40$ years of age. ${ }^{7}$ In our study, abruption was seen in $53.84 \%$ of multigravidae and $46.15 \%$ in primigravidae. In a study by Bhattacharya et al' primigravida accounted for $21.8 \% .{ }^{4}$ Choudhary et al reported that $58.87 \%$ were primigravidae. ${ }^{2}$ The unbooked patients were $92.3 \%$ in our study, probably as our hospital is a tertiary care centre.In the study by Choudhary et al $66.94 \%$ were unbooked. ${ }^{2}$ This is in sharp contrast to the study done by Shabnam Saquib et al where $87 \%$ were booked and the study was done in Dubai. ${ }^{1}$ This reveals the lack of Antenatal care in our patients. In our study, the commonest risk factor was hypertension complicating pregnancy and was found in $26.15 \%$. The study conducted by Saquib et al showed hypertension in $21.7 \% .^{1}$ In the study by Patel et al $50 \%$ had hypertension. ${ }^{9}$ In the study by Yang et al, PIH was seen in $39 \% .^{3}$ In our study $49.23 \%$ underwent caesarean section and $50.76 \%$ were delivered vaginally. In the study by Choudhary et al $45.97 \%$ were cesarean deliveries. ${ }^{2}$ In the study by Patel et al, $40 \%$ were cesarean and $60 \%$ were vaginal delivery. ${ }^{9}$ Regarding the outcome of the fetus, there were $64.17 \%$ live births. These included 2 sets of twins and both underwent Caesarean delivery. In the study by Wasnik et al, 79\% were live births and $69.8 \%$ were live births in the study by Sengodan et al. ${ }^{5,6}$ The major complication in our study was postpartum haemorrhage. It was seen in $16.92 \%$. There was one case of rupture uterus and one had disseminated intravascular coagulation. In the study by Saquib et al $33 \%$ had postpartum haemorrhage and $19.6 \%$ had postpartum haemorrhage in the study by Sengodan et al. ${ }^{1,6}$ Our study showed that $49.2 \%$ of the patients received blood and blood products. Saquib et al reported that $20 \%$ of the patients needed blood transfusion. ${ }^{1}$ Patel et al reported that $95 \%$ received transfusion. ${ }^{9}$ In the study done by Wasnik et al $75 \%$ received transfusion. ${ }^{5}$ None of our patients had renal failure. Choudhary et al reported $10.48 \%$ having acute renal failure. ${ }^{2}$ There was no maternal mortality in our study. Patel et al reported $2.5 \%$ maternal mortality. ${ }^{9}$

\section{Limitations}

Limitations of current study were; this was a retrospective observational study and data was gathered from medical files. There is no comparison with a control group hence statistical significance cannot be drawn for the risk factors. Evaluation of the thrombophilia profiles was not done.

\section{CONCLUSION}

Placental abruption is one of the major complications. Various risk factors are known, but its occurrence is often unpredictable. Adequate antenatal care, early identification of risk factors can help to some extent. Treatment mainly depends on the gestational age and severity of abruption. Timely diagnosis and management preferably in a tertiary care centre, appropriate use of blood and blood products can significantly reduce maternal morbidity and mortality. Perinatal mortality and morbidity is usually due to intra uterine fetal demise and Preterm delivery. With good neonatal intensive care unit, the preterm babies survival is vastly improved.

\section{ACKNOWLEDGEMENTS}

Authors would like to thank M. S. Ramaiah medical college and hospital for supporting the current study.

\section{Funding: No funding sources \\ Conflict of interest: None declared}

Ethical approval: The study was approved by the Institutional Ethics Committee

\section{REFERENCES}

1. Saquib S, Hamza LK, Sayed AA, Saeed F, Abbas M. Prevalence and its fetomaternal outcome in placental abruption : a retrospective study for 5 years from Dubai hospital. Dubai Med J. 2020;3:26-31.

2. Choudhary V, Somani SR, Somani S. Evaluation of risk factors and obstetric and perinatal outcome in 
Abruptio Placenta. IOSR J Dent Med Sci. 2015; 14(5):36-9.

3. Li Y, Tian Y, Liu N, Chen Y, Wu F. Analysis of 62 placental abruption cases: risk factor and clinical outcomes. Taiwanese J Obstet Gynecol. 2019;58: 223-6.

4. Bhattacharya R, Ramesh AC. Pregnancy outcomes in placental abruption in a tertiary care centre in karnataka. Asiana Res J Gynaecol Obstet. 2020; 2(3):1-6.

5. Wasnik SK, Naiknaware SV. Antepartum haemorrhage: causes and its effects on mother and child : an evaluation. 2015;3(1):255-8.

6. Sengodan SS ,Dhanapal M. Abruptio Placenta : a retrospective study on maternal and perinatal outcome. Int J Reprod Contracept Obstet Gynaecol. 2017;6(10):4389-92.

7. Ananth $\mathrm{Cv}$, Lavery JA, Vintzileos AM. Severe placental abruption: clinical definition and association with maternal complications. Am J Obstet Gynecol. 2016;214:272.

8. Shrivatsava V, Kotur P, Jaouhari A. maternal and fetal outcome among abruptio placentae cases at a rural tertiary hospital in karnataka, India: a retrospective analysis. Int J Res Med Sci. 2014;2(4): 1655-8.

9. Patel K, Bhatu J, Patel S. Study of maternal and perinatal outcome in abruptio placentae. Int J Reprod Contracept Obstet Gynecol. 2020;9(5):1882-5.
10. Gaufberg SV. Abruptio placentae. Am J Obstet Gynecol. 2001;42:52-9.

11. Cunningham FG, Macdonald PC, Gant NF, Leveno KJ, Gilstrap III LC, Hankins GDV, et al. Obstetrical Haemorrhage. In: Williams obstetrics $20^{\text {th }}$ ed. USA: Appleton and Lange; 1997:746-55.

12. Hubbard JL, Hosmer SB. USA Couvelaire uterus. J Am Osteopath Assoc. 1997;97(9):536-7.

13. Rasmussen S, Irgens LM, Bergsjo P, Dalaka K.The occurence of placental abruption in Norway 1967-91. Acta Obstet Gynecol Scand. 1996;75(3):222-8.

14. Naeye RL, Harkness Wl, Utts J. Abrutio placentae and perinatal death: a prospective study. Am J Obstet Gynecol. 1977;128(7):740-6.

15. Ananth CV , Berkowitz GS, Savitz DA, Lapinski RH. Placental abruption and adverse perinatal outcomes. J Clin Epidemiol. 1999;52(5):453-61.

16. Salma IK, Stephen AW, Carrol P. Pregancy outcome in severe placental abruption . Br J Obstet Gynaecol. 2003;110:679-83.

Cite this article as: Fernandes JC, Gopalakrishna N. Maternal and fetal outcome in abruptio placentae at a tertiary care centre: a retrospective analysis. Int J Reprod Contracept Obstet Gynecol 2021;10:3860-3. 